\title{
Object-Oriented Mission Modeling for Multiple Transport Aircraft
}

\author{
Jing Zang* and Hu Liu** \\ School of Aeronautic Science and Engineering, Beihang University, Beijing, China
}

\section{Tianping Liu***}

BUAA Research Institute Co., Ltd, Beihang University, Beijing, China

\author{
Xianping $\mathrm{Ni}^{* * * *}$ \\ School of Aeronautic Science and Engineering, Beihang University, Beijing, China
}

\begin{abstract}
A method of multiple transport-aircraft mission modeling is proposed in order to improve the efficiency of evaluating and optimizing pre-mission plans. To deal with the challenge of multiple transport-aircraft missions, the object-oriented modeling method is utilized. The elements of the mission are decomposed into objects and businesses, And the major mission objects and their important properties are summarized. A complex mission can be broken down into basic business modules such as the ground section and flight section. The business models of loading and fueling services in the ground section are described. The business model of the flight section is composed of an air route and flight profile with the flight equation and the fuel consumption model. The logical relationship of objects and business modules is introduced. The architecture of the simulation system, which includes a database, computation module, graphical user interface (GUI) module, and a result analysis module, is established. A sample case that includes two different plans is provided to verify the model's ability to achieve multi-aircraft composite mission simulation.
\end{abstract}

Key words: transport aircraft, mission modeling, object-oriented, air transport

\section{Introduction}

Transport aircraft play a core role in military and civilian airlifts. In the event of unexpected circumstances, such as a major accident or natural disaster, the rapid response capability of transport aircraft has tremendous value. The pre-mission transport plan design and evaluation of the consumption and required resources (such as aircraft type, quantity, etc.) are important tasks to support transportation missions, and to support transport aircraft design.

At present, the research on air transport capability has a wide range. Research on network planning and revenue for commercial air transport is widespread. NASA developed an integrated air transportation system evaluation tool for commercial air transportation [1]. Ulrich Derigs et al. proposed an air cargo network planning approach for a specific air cargo scheduling problem for a major international carrier [2]. Cynthia Barnhart et al. examined airline fleet assignment with enhanced revenue modeling [3]. Yushun Tan and Sengfa Chen analyzed the efficiency of air transport companies based on a network DEA model [4]. In addition, the researchers of Purdue University achieved the integrated optimization of aircraft design and transport network [5-6].

Air traffic management and the operations of an airport area are also important areas of research. NASA Ames Research Center developed a real-time human-in-the-loop Air Traffic Management (ATM) simulation capability for air traffic management research [7]. The future air traffic management
This is an Open Access article distributed under the terms of the Creative Commons Attribution Non-Commercial License (http://creativecommons.org/licenses/by$\mathrm{nc} / 3.0 /$ which permits unrestricted non-commercial use, distribution, and reproduction in any medium, provided the original work is properly cited.

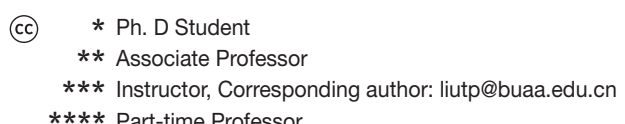

$* * * *$ Part-time Professor 
concepts evaluation tool (FACET) was also developed as a simulation and analysis tool at the NASA Ames Research Center [8]. Nicole Adler et al. benchmarked airports from a managerial perspective by analyzing airports as a single unit due to the direct complementarities [9]. Jie Xiong and Chen Zhang researched airport gate assignment with airplane taxiing cost analysis [10]. Research on the elements of aircraft transportation systems [11] and the pollution of long-range air transportation has also been conducted [12].

The Federal Aviation Administration (FAA) established the National Airspace System (NAS) as a strategy simulation system to support the analysis and decision making of national air transportation [13]. The FAA also developed the Air Carrier Operations System Model (ACOSM) to support a system-safety approach to aviation safety oversight [14]. However, the large scale of NAS may not be suitable for tactical-scale air transport mission simulation. ACOSM concentrates on air carrier operation processes, including operational management, air transportation, aircraft maintenance, personnel training, and operational resource provision to become a standard model for industry and FAA participants, but its application functionality does not focus on setting and analyzing mission plans for transport aircraft. Therefore, it is necessary to develop a modeling and simulation method that focuses on application to transport aircraft to support air transport mission plan evaluation and optimization.

Object-oriented approach is greatly used in research on transportation. Yuqing Pan et al. researched an objectoriented data model for municipal transportation [15]. Shaopei Chen et al. used a spatio-temporal object-oriented modeling method to express the resulting data model for an integrated GIS-based data model [16]. Rodrigo B. Palma et al. proposed a methodology based on an object-oriented model, which identifies and simulates the interdependencies of transportation and energy networks [17]. Autthasith Arrayangkool and Apinetr Unakul developed a flexible intelligent transportation system architecture model with object-oriented methodology and UML (Unified Modeling Language) [18]. Manuel Rossetti and Shikha Nangia researched the design and use of an object-oriented framework for simulating full truckload (FTL) networks [19]. Object-oriented approaches have features of flexibility and reusability [18].

A modeling method is proposed based on the objectoriented approach for complex multiple transport-aircraft missions, including airdrops and transportation between airports. By decomposing and defining the elements of the mission, this method can be used to plan complex missions. This work serves as a basis for developing simulation tools of a complete transport-aircraft mission, which can improve the efficiency of evaluating and optimizing pre-mission plans.

\section{Mission Modeling}

A multiple transport-aircraft mission involves multiple transport aircraft which may carry different loads for different airlines. This kind of mission is complex due to the large number of aircraft, cargo, and airports involved, as well as the complexity of the relationship between the various units. The following difficulties may often be encountered in transport aircraft mission simulations:

- When the mission includes numerous aircraft of different types and the transportation of cargo, the starting point and destination of the aircraft are different, and the relationship of tasks that each aircraft is required to perform is difficult to clarify.

- Because of the complicated relationship of time and space among cargo, aircraft, and airports, errors appear easily in execution if the mission plan is unreasonable.

- Airport resource allocation and multi-plane ground scheduling at the airport often influence each other.

In order to simulate a complex mission of multiple objects running at the same time, the transport aircraft mission is decomposed in this paper. In ACOSM, air transportation is decomposed into air transportation management, passenger services, ground operations, aircraft operations, and air transportation resources [14]. In this study, in contrast to ACOSM, the elements of the multiple transport aircraft mission are divided into objects and businesses, which are defined as the basic tasks or operation steps (Fig. 1). The implementation of each business is participated in by corresponding objects. Every object keeps executing its respective business, and the simulation of the transport

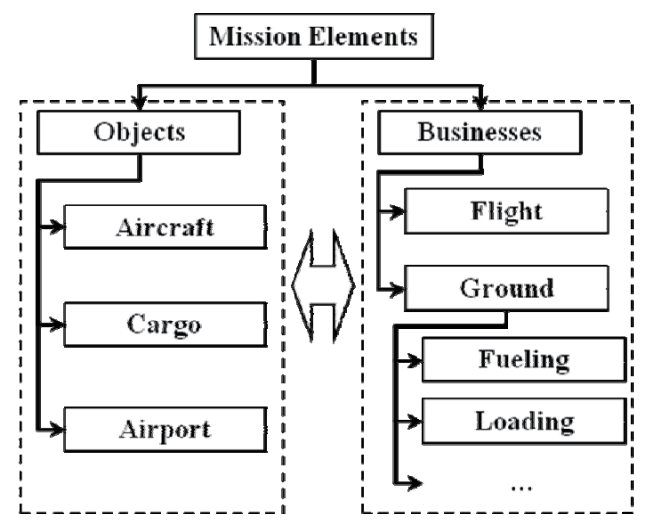

Fig. 1. Decomposition of the Mission 
aircraft mission process is achieved. By this decomposition method, the mission can be reproduced by an objectoriented modeling method. The use of a modular approach for basic business is conducive to mission analysis and software development.

\subsection{Objects of Mission}

A transport aircraft mission includes three main types of objects, which are aircraft, cargo and airports. All of them are important participants in the implementation of the mission. Each type of object has a number of important properties (Fig. 2), which have direct impacts on the mission.

- Aircraft: As the core of the mission, the aircraft's task flow will be regarded as the simulation process. The important properties of aircraft can be divided into two categories, which are load capacity and flight ability. The load capacity includes the cargo bay's size, volume, and maximum load. The flight ability includes speed, altitude, and range.

- Cargo: The location information of cargo, which needs to be tracked in the mission, is the judging criterion of the mission completion. The significant properties of cargo are size and weight, which decide whether the aircraft can deliver the cargo. Passengers are also regarded as a kind of cargo in this paper, since transport aircraft like the IL-76 and C-17 or considered.

- Airport: The role of airport is to provide ground services for aircraft in the mission. The important properties of an airport can be divided into two categories, which are runway parameters and the airport's equipment and crews. The equipment and crews are regarded as parts of the airport rather than independent objects in this paper. Runway parameters (length, pavement classification number, etc.) will affect the takeoff and landing of aircraft. Equipment and crews will affect the airport's support capacity.

In addition, the mission environment object, which includes elements of the natural environment such as the terrain and weather, and facilities such as the navigation

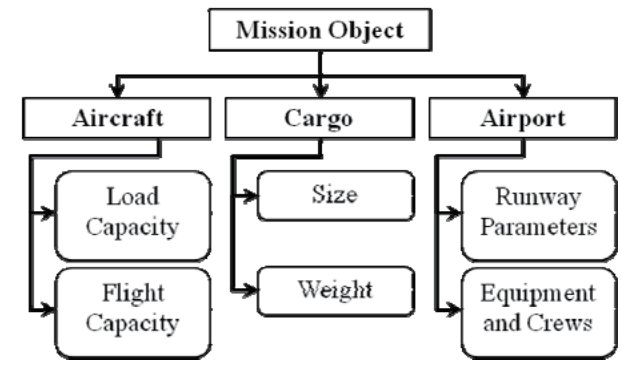

Fig. 2. Important properties of mission objects station, will only be considered as environmental parameters of mission modeling in this paper.

\subsection{Business Module}

As the core object of the mission, the requirement of the aircraft determines the selection criteria of the basic business is, and each business needs the participation of the aircraft . The business in a transport aircraft mission can be divided into ground and flight sections, and the ground section can be divided into separate ground service businesses.

\subsubsection{Ground Section}

The business of the ground section includes cargo loading/off-loading, fueling, examination, and repairing . The cargo loading/off-loading and fueling are more complex than other services. The cargo loading/off-loading contains all three mission objects, and fueling affects the aircraft's take-off weight and endurance. Other ground service can be simplified as a period of time, but these two types cannot.

Figure 2 shows the business model of loading and offloading services for aircraft at the airport. There are three types of objects in this business: aircraft, airport and cargo. The thick arrow with the cargo inside means the operation of loading or off-loading, and the dotted arrows represent the information flow of each object. Cargo is loaded to or off-loaded from the aircraft through the airport's loading equipment and crews. The type of loading or off-loading determines the number and the type of the required loading equipment and crews. Time consumption is determined by the type and quantity of the cargo and the type of loading or off-loading together.

The three objects record their own data of each loading or off-loading task (represented by rounded rectangles in Fig.3):

- Cargo: Cargo will record information such as the aircraft's ID, its transportation history, loading type, and

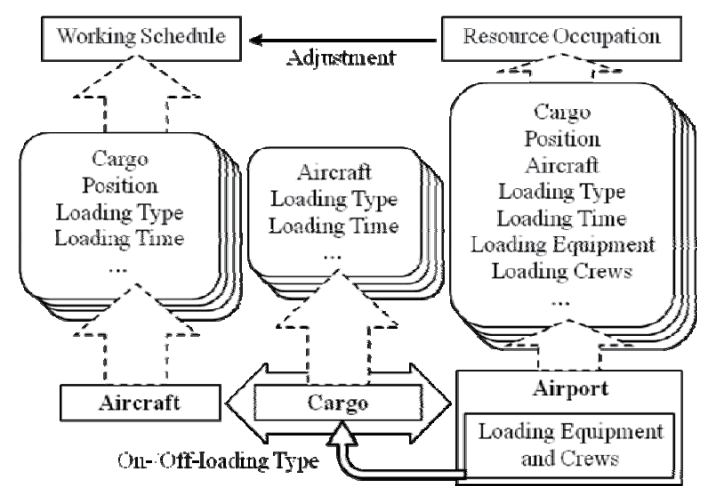

Fig. 3. Business model of loading and off-loading services 
loading time.

- Airport: The airport will record information such as the ID of the loaded cargo, the aircraft's ID, loading position, loading type, loading time, loading equipment and crews, etc. This information is summarized with the other airport ground services' information to calculate the airport's resource consumption. The airport will adjust each aircraft's scheduling of ground services at the airport based on the resource occupation in the process of mission simulation.

- Aircraft: Aircraft will record information such as the ID of the cargo which is loaded, as well as the loading position, loading type, loading time, loading equipment, and crews. With the other ground service information, this information will provide support for the aircraft's scheduling of ground services at the airport, which will eventually be used in the aircraft's working scheduling table.

The business model of fueling (Fig. 4) is very similar to the loading and off-loading. But the objects of this business are only aircraft and airport. In addition, the aircraft and airport need to record the changes in their own fuel capacities.

\subsubsection{Flight Section}

The business of flight is accomplished independently by the aircraft object, because the location change of the loaded cargo will be the same as that of the aircraft, without the need for separate calculation. The airdrop process is simplified without specific modeling. When the aircraft flies over the airdrop point, leaving the cargo, the cargo will be considered to have landed at the target area. Figure 5 shows the business model of flight, in which a single flight is composed of an air route and flight profile. Each rounded rectangle represents a single flight.

A single flight's air route connects one airport to another,

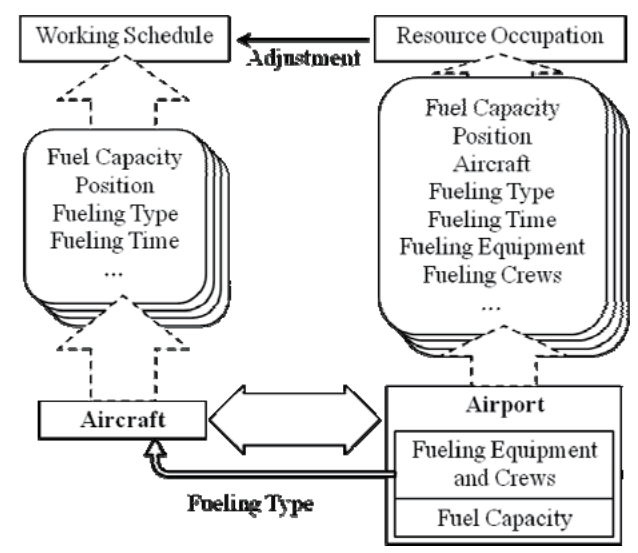

Fig. 4. Business model of fueling service and should include the airdrop point when there is an airdrop in this flight to ensure the aircraft to fly over the airdrop area. Usually, standard routes are preferred in air transport missions between two airports, which can be selected directly from a database. However, setting a temporary air route is necessary in airdrop missions.

The flight profile should be set based on the air route. In addition to the typical profile segments such as climb, cruise, and decline, airdrop segments should also be included in the flight profile. While flying in accordance with the air route and flight profile, the aircraft's flight status will be calculated through the flight equation, and its fuel status will be calculated through the fuel consumption model. The flight equation can be in different levels of the algorithm such as particle dynamics or particle kinematics, and a data interface is provided in software to facilitate a user's selection.

\subsection{Logical Relationship}

The independent business modules should be linked to achieve a completed mission simulation (Fig. 6). As the core of a mission, each flight of an aircraft object can be seen as a separate subtask of the entire mission. Every completed flight is composed of two ground sections and a flight section, and shares one ground section with the next flight. A single flight

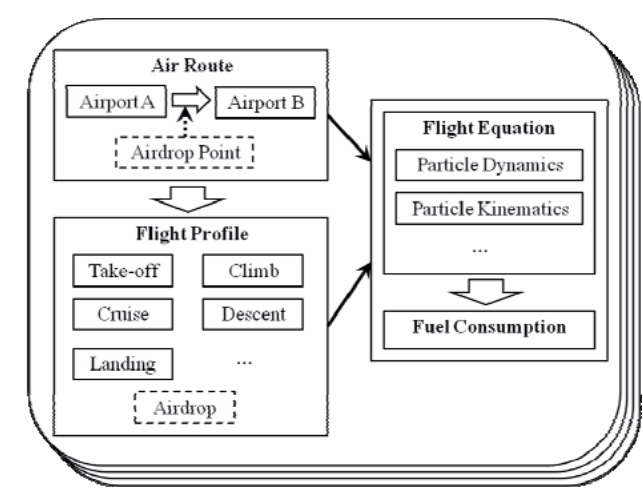

Fig. 5. Business model of flight

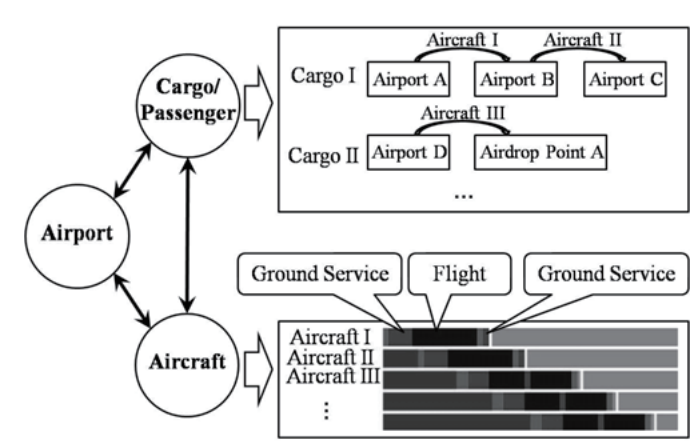

Fig. 6. Logical relationship 
could transport cargo from one airport to another, or could also be an airdrop or just a ferry flight. The multiple flights of this aircraft's mission, along with multiple other aircrafts, can comprise a complex multi-aircraft mission simulation for a variety of tasks.

The location information of cargo is the judging criterion of the mission completion. A single flight of cargo can be seen as a separate subtask of the cargo. In Fig. 6, Cargo I has flown two times with Aircraft I and Aircraft II to be transferred from airport A to airport $\mathrm{C}$ in the mission. Cargo II has been dropped at the airdrop point A from the airport D. In addition, the airport object plays a supporting role in the management and deployment of its own resources in the simulation.

\section{Architecture of Simulation System}

A software platform must be built to test the model of multiple transport-aircraft missions through simulations. The object-oriented mission modeling makes the software development more convenient. The simulation system is shown in Fig. 7. The system comprises four main modules: the database, computation module, graphical user interface (GUI) module, and result analysis module.

- Database: The parameter section is used for storing parameters of individual objects in the simulation, such as the aircraft's load and maximum takeoff weight. The process of data section records the status information of individual objects during the simulation, such as the cargo's position and its aircraft. The plan section's duty is to manage the setting information of each mission simulation for the multiple calculations of the same plan. The plan section can also be used for the contrast of the different plans.

- Computation module: This module is the core of the system, through which the simulation process is driven by various objects and business modules.

- Result analysis module: The result analysis module summarizes the simulation data and performs computations based on an effectiveness-evaluation algorithm. Finally, a report is generated by the result module for the user.

- Graphical user interface (GUI) module: The map submodule's main duty is to visually display the process and results of the simulation. Users can set the plans of a mission through the operation sub-module.

\section{Sample Case}

A sample case that includes two different plans is used to verify the model's ability to achieve a multi-aircraft composite mission simulation for plan evaluation. This case is an air transport mission for a sudden epidemic rescue in Guangzhou.

\subsection{Mission Plans}

The simulations of the two plans are achieved by the object-oriented multiple transport-aircraft mission modeling method.

\subsubsection{Mission Objects}

- Cargo: The cargo objects in the mission include ten pallets of relief supplies and six ambulances in Beijing, four ambulances in Shanghai, and four pallets of relief supplies in Xi'an. All the cargo objects should be sent to Guangzhou in the mission.

- Airport: The airport objects active in the mission are located in Beijing, Shanghai, Xi'an, and Guangzhou.

- Aircraft: The aircraft objects in the two plans are different There are two A-type aircraft objects comprising fleet I, and three B-type aircraft objects comprising fleet II located in Beijing, as well as two B-type aircraft objects located in Shanghai comprising fleet III at the beginning of plan I. There are four A-type aircraft objects located in Beijing comprising fleet A, and two A-type aircraft
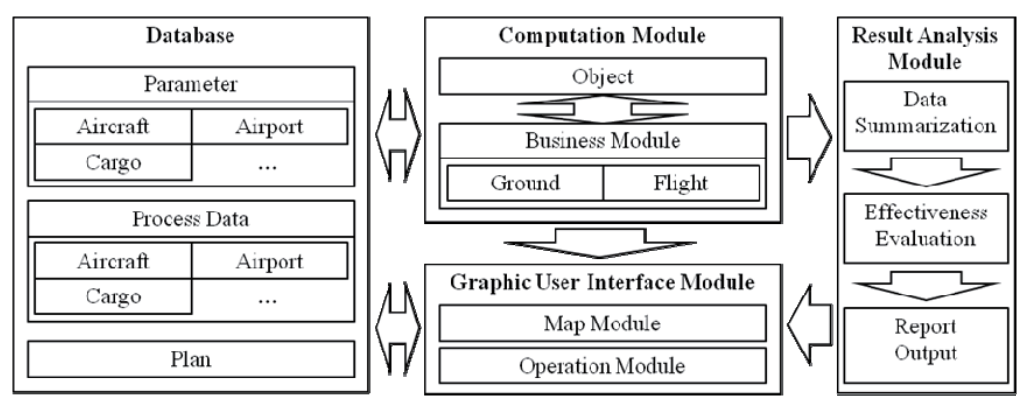

Fig. 7. Architecture of simulation system 
objects located in Shanghai comprising fleet B at the beginning of plan II. An A-type aircraft has higher cargo capacity and longer range than a B-type aircraft.

\subsubsection{Mission Process}

In plan I, fleet I directly flies from Beijing to Guangzhou and fleet II flies from Beijing to Guangzhou with a stopover in Shanghai, carrying cargo,. Fleet III firstly flies from Beijing to Guangzhou to transport the cargo from Shanghai, and then this fleet flies to Xi'an to load the cargo of Xi'an and finally transports the cargo to Guangzhou (Fig. 8).

In plan II, fleet A directly flies from Beijing to Guangzhou, carrying cargo. After loading cargo in Shanghai, fleet B flies to Xi'an to load more cargo and transport all the cargo to Guangzhou (Fig. 9).

\subsubsection{Mission Businesses}

The mission businesses and the achievement of the mission can be illustrated by the following example of fleet III in plan I, because the mission process of this fleet is the most complex among the two plans. The businesses and mission

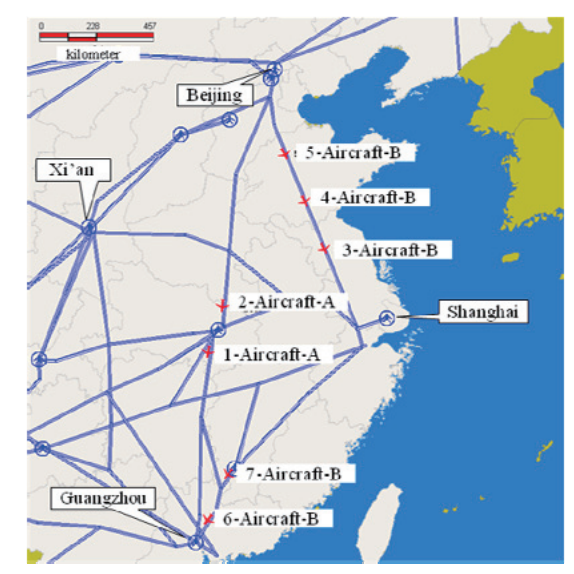

Fig. 8. Simulation of plan I process of fleet III are shown in Fig 10. The two overlapping rectangles represent the processes of the two B-type aircraft of fleet III. Because the mission processes are the same, only one aircraft's information is listed. Each aircraft of fleet III has three flights (from one airport to another), which include four ground sections and three flight sections in the mission. For example, the ground section in Shanghai has six businesses, which are taxiing for service, repairing, fueling, on/off-loading, taxiing for flight, and waiting in sequence. In on/off-loading business, the aircraft should load two ambulances. Other ground sections are the same with different detailed settings, such as different cargo in on/off-loading business. In the flight section from Shanghai to Guangzhou, the aircraft has seven flight profiles, which include take-off, climb, decelerating, cruise, accelerating, descent, and landing on the air route. All the flight sections have the same number of profiles with different settings.

\subsection{Result Analysis}

The data of the example is shown in Table 1. It can be seen from the results that to transport the same cargo, plan II will

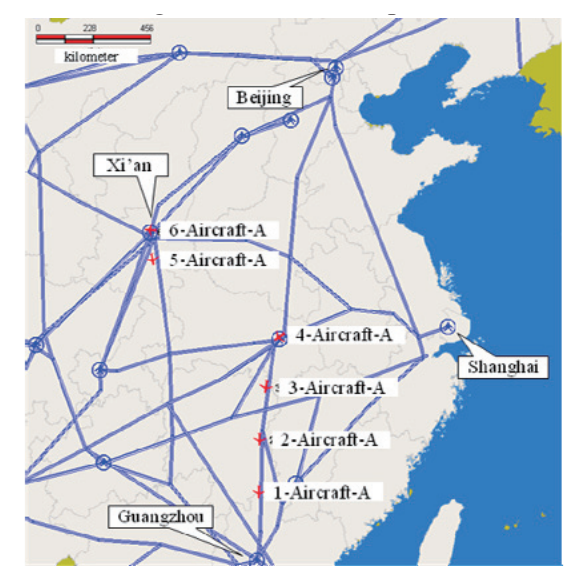

Fig. 9. . Simulation of plan II

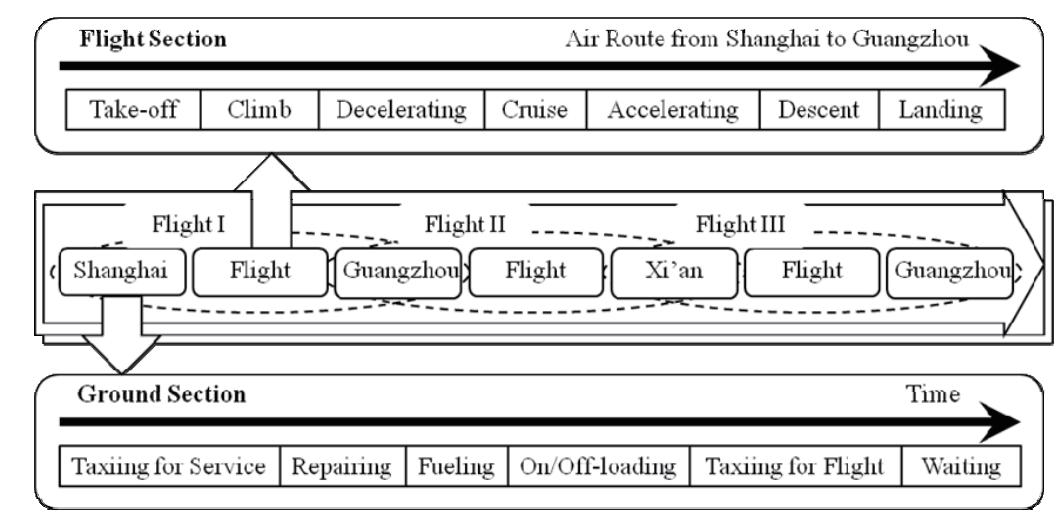

Fig. 10. Mission businesses of fleet III 
Table 1. Data of sample case

\begin{tabular}{|c|c|c|c|c|c|c|c|c|c|c|c|c|c|c|}
\hline \multirow{9}{*}{ 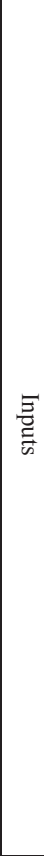 } & Plan & \multicolumn{7}{|c|}{ Plan I } & \multirow{2}{*}{\multicolumn{6}{|c|}{$\begin{array}{c}\text { Plan II } \\
\text { Aircraft A }\end{array}$}} \\
\hline & $\begin{array}{l}\text { Aircraft } \\
\text { type }\end{array}$ & \multicolumn{2}{|c|}{ Aircraft A } & \multicolumn{3}{|c|}{ Aircraft B } & \multicolumn{2}{|c|}{ Aircraft A } & & & & & & \\
\hline & $\begin{array}{c}\text { Numbers } \\
\text { of } \\
\text { aircraft }\end{array}$ & 1 & 2 & 3 & 4 & 5 & 6 & 7 & 1 & 2 & 3 & 4 & 5 & 6 \\
\hline & Load & $\begin{array}{c}463 \\
\text { L } \\
\text { Palle } \\
\mathrm{t} * 5 \\
\text { (in } \\
\text { Beiji } \\
\text { ng) }\end{array}$ & $\begin{array}{c}463 \\
\text { L } \\
\text { Palle } \\
t * 5 \\
\text { (in } \\
\text { Beiji } \\
\text { ng) }\end{array}$ & $\begin{array}{c}\text { Ambul } \\
\text { ance } \\
* 2 \text { (in } \\
\text { Beijin } \\
\text { g) }\end{array}$ & $\begin{array}{c}\text { Ambul } \\
\text { ance } \\
* 2 \text { (in } \\
\text { Beijin } \\
\text { g) }\end{array}$ & $\begin{array}{c}\text { Ambul } \\
\text { ance } \\
* 2 \text { (in } \\
\text { Beijin } \\
\text { g) }\end{array}$ & $\begin{array}{c}\text { Ambul } \\
\text { ance } \\
* 2 \text { (in } \\
\text { Shang } \\
\text { hai) } / \\
463 \mathrm{~L} \\
\text { Pallet } \\
* 2 \text { (in } \\
\text { Xi'an) }\end{array}$ & $\begin{array}{c}\text { Ambul } \\
\text { ance } \\
* 2 \text { (in } \\
\text { Shang } \\
\text { hai) / } \\
463 \mathrm{~L} \\
\text { Pallet } \\
* 2 \text { (in } \\
\text { Xi'an) }\end{array}$ & $\begin{array}{c}463 \\
\text { L } \\
\text { Palle } \\
\mathrm{t} * 5 \\
\text { (in } \\
\text { Beiji } \\
\text { ng) }\end{array}$ & $\begin{array}{c}463 \\
\text { L } \\
\text { Palle } \\
\text { t*5 } \\
\text { (in } \\
\text { Beiji } \\
\text { ng) }\end{array}$ & $\begin{array}{c}\text { Ambul } \\
\text { ance } \\
* 3 \text { (in } \\
\text { Beijin } \\
\text { g) }\end{array}$ & $\begin{array}{c}\text { Ambul } \\
\text { ance } \\
* 3 \text { (in } \\
\text { Beijin } \\
\text { g) }\end{array}$ & $\begin{array}{c}\text { Ambul } \\
\text { ance } \\
* 2 \text { (in } \\
\text { Shang } \\
\text { hai) }+ \\
463 \mathrm{~L} \\
\text { Pallet } \\
* 2 \text { (in } \\
\text { Xi'an) }\end{array}$ & $\begin{array}{c}\text { Ambul } \\
\text { ance } \\
* 2 \text { (in } \\
\text { Shang } \\
\text { hai) + } \\
463 \mathrm{~L} \\
\text { Pallet } \\
* 2 \text { (in } \\
\text { Xi'an) }\end{array}$ \\
\hline & $\begin{array}{c}\text { Load } \\
\text { weight }\end{array}$ & $22.5 \mathrm{t}$ & $22.5 \mathrm{t}$ & $8 \mathrm{t}$ & $8 \mathrm{t}$ & $8 \mathrm{t}$ & $8 \mathrm{t} / 9 \mathrm{t}$ & $8 \mathrm{t} / 9 \mathrm{t}$ & $22.5 \mathrm{t}$ & $22.5 \mathrm{t}$ & $12 \mathrm{t}$ & $12 \mathrm{t}$ & $8 t+9 t$ & $8 \mathrm{t}+9 \mathrm{t}$ \\
\hline & $\begin{array}{c}\text { Starting } \\
\text { airport }\end{array}$ & \multicolumn{5}{|c|}{ Beijing Capital International Airport } & \multicolumn{2}{|c|}{$\begin{array}{c}\text { Shanghai } \\
\text { Hongqiao } \\
\text { Airport } \\
\end{array}$} & \multicolumn{4}{|c|}{$\begin{array}{c}\text { Beijing Capital International } \\
\text { Airport }\end{array}$} & \multicolumn{2}{|c|}{$\begin{array}{c}\text { Shanghai } \\
\text { Hongqiao } \\
\text { Airport } \\
\end{array}$} \\
\hline & $\begin{array}{c}\text { Stopover } \\
\text { airport I }\end{array}$ & \multicolumn{2}{|c|}{ 一 } & \multicolumn{3}{|c|}{$\begin{array}{l}\text { Shanghai Hongqiao } \\
\text { Airport }\end{array}$} & \multicolumn{2}{|c|}{$\begin{array}{c}\text { Guangzhou } \\
\text { Baiyun } \\
\text { International } \\
\text { Airport } \\
\end{array}$} & & & - & & \multicolumn{2}{|c|}{$\begin{array}{c}\text { Xi'an Xianyang } \\
\text { International } \\
\text { Airport }\end{array}$} \\
\hline & $\begin{array}{l}\text { Stopover } \\
\text { airport II }\end{array}$ & \multicolumn{2}{|c|}{ - } & & - & & $\begin{array}{r}\text { Xi'an } \mathrm{X} \\
\text { Intern } \\
\mathrm{Ai} \\
\end{array}$ & $\begin{array}{l}\text { anyang } \\
\text { tional } \\
\text { ort } \\
\end{array}$ & & & - & & & \\
\hline & $\begin{array}{l}\text { Destinati } \\
\text { on airport }\end{array}$ & \multicolumn{7}{|c|}{ Guangzhou Baiyun International Airport } & \multicolumn{6}{|c|}{ Guangzhou Baiyun International Airport } \\
\hline \multirow{4}{*}{ 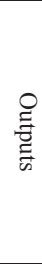 } & $\begin{array}{l}\text { Mission } \\
\text { time }\end{array}$ & \multicolumn{7}{|c|}{$7.91 \mathrm{~h}$} & \multicolumn{6}{|c|}{$5.91 \mathrm{~h}$} \\
\hline & $\begin{array}{c}\text { Total } \\
\text { distance }\end{array}$ & \multicolumn{7}{|c|}{$19704 \mathrm{~km}$} & \multicolumn{6}{|c|}{$13254 \mathrm{~km}$} \\
\hline & $\begin{array}{c}\text { Total } \\
\text { transport }\end{array}$ & \multicolumn{7}{|c|}{$103 \mathrm{t}$} & \multicolumn{6}{|c|}{$103 \mathrm{t}$} \\
\hline & $\begin{array}{c}\text { Total fuel } \\
\text { consumpt } \\
\text { ion } \\
\end{array}$ & \multicolumn{7}{|c|}{$245955.94 \mathrm{~kg}$} & \multicolumn{6}{|c|}{$197521.27 \mathrm{~kg}$} \\
\hline
\end{tabular}

take a shorter time and consume less fuel than plan I by using larger transport aircraft, even though there are fewer aircraft. Therefore, the plans can be evaluated and compared through the simulation system based on this method. In this sample case, by setting the mission objects and businesses through the proposed modeling method, a relatively complex mission can be achieved through the basic simple steps.

\section{Conclusion}

An object-oriented method for multiple transport-aircraft mission modeling has been presented. In order to simulate missions, they are decomposed into basic businesses and aircraft, cargo, and airport mission objects. The businesses can be divided into ground section and flight section types. The various basic businesses are performed by every object to achieve the entire mission simulation. A sample case of two different plans was presented for the verification of the model.

By combining the basic steps, complex mission simulation can be achieved by the proposed modeling method. Provided as a basis for research on transport-aircraft mission simulation tools, this model can be used for pre-mission plan evaluation and optimization for various air transport missions, like humanitarian relief, peacekeeping operations, and disaster relief. It can also support commercial air transport assessment or effectiveness evaluation for different types of transport aircraft.

However, this modeling method is quite rough regarding the details of missions in its current state. In future research, the capacity of the model will be reinforced in the following regards:

- The refined modeling for the services of the ground section.

- Extending the range of the application by combining the current transport aircraft mission with a wide-area air transportation system.

- Adopting agent-based modeling method to improve the capability for complex mission.

- Developing a special plan evaluation and optimization tool to improve the efficiency of the application. The optimization will be achieved by iterating and comparing 
the simulation with different mission plan setting.

\section{Acknowledgement}

The authors wish to thank Ming Tong for support in the development of the software.

\section{References}

[1] Earl, W. III, Jing, H., and James, V., "The Integrated Air Transportation System Evaluation Tool”, NASA CR-2002211961, 2002.

[2] Ulrich, D., Stefan, F., and Simon, S., "A New Approach for Air Cargo Network Planning", Transportation Science, Vol. 43, No. 3, 2009, pp. 370-380.

[3] Cynthia, B., Amr, F., and Manoj, L., "Airline Fleet Assignment with Enhanced Revenue Modeling", Operations Research, Vol. 57, No. 1, 2009, pp. 231-244.

[4] Yushun, T., and Sengfa, C., "Analyses on efficiency of air transport companies based on network DEA", Journal of Southeast University (Natural Science Edition), Vol. 41, No. 5, 2011, pp. 1114-1118.

[5] Muharrem, M., William, C., and Nusawardhana, "System-of-Systems Inspired Aircraft Sizing and Airline Resource Allocation via Decomposition", Journal of Aircraft, Vol. 44, No. 4, 2007, pp. 1222-1235.

[6] Navindran, D., and William, C., "Concurrent Aircraft Design and Airline Network Design Incorporating Passenger Demand Models", Aviation Technology, Integration, and Operations Conference (ATIO), AIAA 2009-6971, South Carolina, 2009, pp. 1-10.

[7] Barry, S. and Scott, M., "Development of a realtime virtual airspace simulation capability for air traffic management research", AIAA Modeling and Simulation Technologies Conference and Exhibit, AIAA 2002-4592, Monterey, California, 2002, pp. 1-6.

[8] Bilimoria, K., Sridhar, B., Chatterji, G., Kapil, S., and Shon, G., "FACET: Future Air Traffic Management Concepts Evaluation Tool", Air Traffic Control Quarterly, Vol. 9, No. 1, 2001, pp. 1-20.

[9] Nicole, A., Vanessa, L., and Ekaterina, Y., "Benchmarking airports from a managerial perspective”, Omega, Vol. 41, No.
2, 2013, pp. 442-458.

[10] Jie, X., and Chen Z., "Airport Gate Assignment with Airplane Taxiing Cost Analysis", Journal of Transportation Systems Engineering and Information Technology, Vol. 10, No. 3, 2010, pp. 165-169.

[11] Viken, S., and Brooks, F., "Demonstration of Four Operating Capabilities to Enable a Small Aircraft Transportation System", 24 $4^{\text {th }}$ Digital Avionics Systems Conference, Washington, DC, United States, Vol. 2, 2005, pp. 1-16.

[12] Jacob, B., "A cluster analysis of long range air transport pathways and associated pollutant concentrations within the UK", Atmospheric Environment, Vol. 44, No. 4, 2010, pp. 563-571.

[13] Zhencai, T., "The Introduction of FAA NAS Strategy Simulation System", Air Traffic Management, Vol. 13, No. 10, 2007, pp. 16-19.

[14] Office of Aviation Research, "Air Carrier Operations System Model”, U.S. Federal Aviation Administration, United States, 2001.

[15] Yuqing, P., Yehua, S., and Guiying, Z., “Objectoriented Data Model of the Municipal Transportation", Geoinformatics 2008 and Joint Conference on GIS and Built Environment: The Built Environment and Its Dynamics, Guangzhou, China, Vol. 7144, 2008, pp.1-9.

[16] Shaopei, C., Jianjun, T., C., Ray, C., Claramunt, and Qinqin S., "An integrated GIS-based data model for multimodal urban public transportation analysis and management", Geoinformatics 2008 and Joint Conference on GIS and Built Environment: The Built Environment and Its Dynamics, Guangzhou, China, Vol. 7144, 2008, pp.1-12.

[17] Rodrigo, P., Luis, V., Fernando, F., and Nolberto, O., "Object oriented platform for an integrated analysis of energy and transportation networks", IEEE Transactions on Power Systems, Vol. 18, No. 3, 2003, pp. 1062-1069.

[18] Autthasith, A., and Apinetr, U., "A flexible intelligent transportation system architecture model with object oriented methodology and UML", $9^{\text {th }}$ International Symposium on Communications and Information Technology, Icheon, Korea, 2009, pp. 741-746.

[19] Manuel, R., and Shikha, N., "An object-oriented framework for simulating full truckload transportation networks", 2007 Winter Simulation Conference, Washington DC, United States, 2009, pp. 1869-1877. 